\title{
Down-Regulation of Laminin (LN)- $\alpha 5$ is Associated with Preeclampsia and Impairs Trophoblast Cell Viability and Invasiveness Through PI3K Signaling Pathway
}

\author{
Xue Mei Zhang ${ }^{\mathrm{a}} \quad$ Xi Xiong ${ }^{\mathrm{a}} \quad$ Chao Tong $^{\mathrm{a}}$ Qin Lia Shuai Huang ${ }^{\mathrm{a}}$ Qing Shu Li ${ }^{\mathrm{b}}$ \\ Ya Ming Liu ${ }^{a}$ Hai Ying Li ${ }^{a}$ Phillip Baker ${ }^{c}$ Nan Shan ${ }^{a}$ Hong Bo Qi ${ }^{a}$ \\ aDepartment of Obstetrics, The First Affiliated Hospital, Chongqing Medical University, Chongqing, \\ bepartment of Pathology, Chongqing Medical University, Chongqing, China, 'College of Medicine, \\ Biological Sciences and Psychology, University of Leicester, Leicester, United Kingdom
}

\section{Key Words}

Laminin (LN)- $\alpha 5 \cdot$ Trophoblast • Preeclampsia • PI3K signaling pathway

\begin{abstract}
Background/Aims: Preeclampsia (PE) is a gestational disorder defined as hypertension and proteinuria, which is deemed a major cause of maternal and neonatal mortality and morbidity worldwide. The aim of this study was to investigate the expression patterns of placental laminin (LN)- $\alpha 5$ expression in normal and PE pregnancies, as well as evaluating the effects of LN- $\alpha 5$ on trophoblast proliferation, apoptosis, and invasion. Methods: $L N-\alpha 5$ expression levels were examined by reverse-transcriptase polymerase chain reaction (RT-PCR), and further confirmed by western blotting and immunofluorescence staining. Cell proliferation and apoptosis were measured by CCK-8 assay and flow cytometry. Cell invasion was assessed by matrigel-based transwell assay. $L N-\alpha 5$ DNA methylation in placentas was determined by bisulfite sequencing PCR (BSP). Results: $L N-\alpha 5$ expression levels in PE placentas were significantly lower than that of normal pregnancies. Deficiency in $\mathrm{LN}-\alpha 5$ expression resulted in decreased trophoblast proliferation and invasion but increased cell apoptosis, meanwhile, PI3K/AKT/mTOR signaling pathway was impaired by $\mathrm{LN}-\alpha 5$ silencing. $\mathrm{LN}-\alpha 5$ promoter methylation didn't show significant difference between PE and normal placentas. Conclusion: $\mathrm{LN}-\alpha 5$ downregulation is associated with PE placenta and impairs trophoblast viability and invasiveness, which could be a causative factor of PE pathogenesis.
\end{abstract}




\section{Introduction}

Preeclampsia (PE) is a pregnancy specific disorder usually occurs after 20 weeks of gestation, and defined as newly diagnosed hypertension accompanied by proteinuria. The incidence of $\mathrm{PE}$ is $3 \%$ to $7 \%$ of all pregnancies, and it is a major cause of maternal and neonatal mortality and morbidity worldwide $[1,2]$. Studies on the etiology and pathogenesis of PE have shown the involvement of various factors such as inadequate trophoblast invasion and abnormal placental development in PE development $[3,4]$; however, the exact causes of PE remain unclear.

Laminins (LNs) are the best-described extracellular matrix (ECM) constituents that influence cell adhesion [5]. LNs are composed of three subunits, designated $\alpha, \beta$ and $\gamma$ chains, which assemble into a cross-shaped trimer to form 16 different isoforms [6-8]. The most widely expressed LN subunit in adult basement membranes is the laminin- $\alpha 5$ chain (LN- $\alpha 5$ ) [9]. Unique developmental roles of $\mathrm{LN}-\alpha 5$ have been studied in knockout (LN5-KO) mice since 1998, the result demonstrated embryos lacking LN- $\alpha 5$ die late in embryogenesis, and exhibit multiple developmental defects, including exencephaly, syndactyly and dysmorphogenesis of placental labyrinth. [10]. Some studied suggested that LN- $\alpha 5$ were present within the basement membranes (BMs) of skin, skeletal muscle, lung, intestine, retina and kidney, and as the structural protein, so the $\mathrm{LN}-\alpha 5$ had an outstanding biological role $[11,12]$. For example, Ritie' and colleagues reported that the presence of malformed intestine in $\mathrm{LN}-\alpha 5$ deficient mice is caused by abnormal wingless-type MMTV integration site family member(Wnt) and phosphoinositide 3-kinase (PI3K) signaling [13]. The role of LN- $\alpha 5$ in promoting dermal papilla development and its function during early hair morphogenesis had been reported in mouse [14]. In addition, Simone and colleagues demonstrated the disease phenotype associated with $\mathrm{LN}-\alpha 5$ mutation in humans including skin anomalies, impaired scarring, night blindness, muscle weakness, osteoarthritis, joint and internal organs ligaments laxity, malabsorption syndrome and hypothyroidism [15]. Thus, the qualitative and quantitative expressions of $\mathrm{LN}-\alpha 5$ were different during the development stage as the regulatory molecules.

It is known that $\mathrm{PI} 3 \mathrm{~K} /$ serine-threonine protein kinase $\mathrm{B} /$ mammalian target of rapamycin (PI3K/Akt/mTOR) signaling pathway plays important regulatory roles in cell migration, invasion, and apoptosis in variety cancers including breast cancer, prostate cancers, melanomas, and so on [16]. Mouse studies have demonstrated that $\mathrm{LN}-\alpha 5$ has been shown crucial for embryonic intestinal epithelial and mesenchymal cell behaviors through the inhibition of Wnt and activation of PI3K signaling [13]. Considering that trophoblast cells and cancer cells share many similarities in cell proliferation, migration and invasion, LN$\alpha 5$ is a plausible causative factor for PE probably by regulating PI3K/Akt/mTOR signaling pathway in trophoblast. In this study, we investigated the expression patterns of LN- $\alpha 5$ in human placentas and assessed mechanisms by which LN- $\alpha 5$ may be involved in the pathogenesis of PE.

\section{Materials and Methods}

Patients recruitment and tissue collection

Placentae were obtained from $\mathrm{PE}$ (35.33 \pm 2.39 weeks, $n=20)$ and normal pregnancy (34.71 \pm 1.92 weeks, $n=20)$ between March 2016 and May 2017 at the First Affiliated Hospital of Chongqing Medical University, Chongqing, China. PE was diagnosed according to the guidelines of the U.S. National Institutes of Health (U.S.
Table 1. Clinical characteristics of participants $(n=20)$

\begin{tabular}{lccc}
\hline Category & Control & Preeclampsia & P value \\
\hline Patient age (year) & $33.47 \pm 5.42$ & $30.19 \pm 5.37$ & 0.056 \\
Gestational age (week) & $34.71 \pm 1.92$ & $35.33 \pm 2.39$ & 0.362 \\
Body mass index $\left(\mathrm{kg} / \mathrm{m}^{2}\right)$ & $22.90 \pm 2.32$ & $22.38 \pm 2.24$ & 0.462 \\
Proteinuria (g/24 h) & - & $3.47 \pm 0.92$ & - \\
Systolic blood pressure $(\mathrm{mmHg})$ & $120.19 \pm 7.60$ & $162.26 \pm 5.62$ & 0.000 \\
Diastolic blood pressure $(\mathrm{mmHg})$ & $73.90 \pm 4.03$ & $105.71 \pm 5.72$ & 0.000 \\
Neonatal birth weight $(\mathrm{g})$ & $3373.80 \pm 308.52$ & $2515.23 \pm 161.07$ & 0.000 \\
\hline
\end{tabular}




\section{Cellular Physiology Cell Physiol Biochem 2018;51:2030-2040 \begin{tabular}{l|l|l} 
and Biochemistry & $\begin{array}{l}\text { DOI: 10.1159/000495822 } \\
\text { Published online: 6 December } 2018\end{array}$ & $\begin{array}{l}\text { @ } 2018 \text { The Author(s). Published by S. Karger AG, Basel } \\
\text { www.karger.com/cpb }\end{array}$
\end{tabular}}

Zhang et al.: Role of Laminin (LN)- $\alpha 5$ in Preeclampsia Placentas

National High Blood Pressure Education Program 2000). Placental tissues were obtained immediately after delivery by caesarean section. Small pieces $\left(\sim 0.5 \mathrm{~cm}^{3}\right)$ were cut from the maternal part of the placentas under aseptic conditions and washed briefly with sterile PBS to remove maternal blood clots. All samples were frozen within $15 \mathrm{~min}$ after delivery and stored in liquid nitrogen for western blot and immunofluorescence analyses. The clinical details of participants are summarized in Table 1. The collection and use of placental samples was approved by the Ethical Committee of the First Affiliated Hospital of Chongqing Medical University, and written informed consent was provided by all participants.

\section{Cell culture and treatments}

To assess the function of $\mathrm{LN}-\alpha 5$ in vitro, human trophoblast cell line HTR-8/SVneo, which was kindly provided by Dr. Charles H. Graham (Kingston, ON, Canada), has been used. HTR-8/SVneo cells were cultured in Roswell Park Memorial Institute (RPMI) 1640 media (Gibco, MA, USA) that containing 10\% fetal bovine serum (FBS) (Gibco, MA, USA). In the control group, cells were incubated in $5 \% \mathrm{CO}_{2}$ at $37{ }^{\circ} \mathrm{C}$, while, the $\mathrm{H} / \mathrm{R}$ group was performed as follows: 8 hours under $2 \%$ oxygen followed by transfer to standard culture condition with 20\% oxygen for 16 hours [17]. PI3K inhibitor LY294002 (2-(4-morpholinyl)-8-phenyl-4H1-benzopyran-4-one) was purchased from Selleck Biochemicals (LY, Houston, USA), which was diluted with dimethylsulfoxide (DMSO) [18]. The HTR8/SVneo cells were pre-incubated with 20 uM LY294002 for 24 hours.

\section{RNA interference}

The LN- $\alpha 5$ siRNA sequences (5'-GCATCAGCTTCGACAGTCA-3') and scramble RNA were synthesized by Ribobio (Guangzhou, China). HTR8/SVneo cells were transiently transfected with either LN- $\alpha 5$ siRNA or scramble RNA as a control by using Lipofectamine 2000 (Invitrogen, USA) according to the manufacturer's protocol. The transfection efficiency was further assessed by western blot.

$q P C R$

qPCR was performed as previously described [19]. Briefly, total RNA was isolated from cells or tissues by the use of Trizol (Takara Biotechnology Co. China), and then reverse-transcription to cDNA was performed by the use of Superscript II First-Strand Synthesis System (Takara Biotechnology, Japan). Primers are listed in Table 2.

\section{Western blotting}

Proteins extracted from tissues or cells were subjected to western blot as previous reported by our group [19]. Primary antibodies against western blotting: LN- $\alpha 5$ (1:1000; Abcam, ab184330), Akt (1:1000; Cell Signaling Technology, \#9272), p-Akt (Ser473) (1:1000; Cell Signaling Technology, \#9271), mTOR (1:1000; Cell Signaling Technology, \#2983) and p-mTOR (Ser2481) (1:1000; Abcam, ab137133) were used. Protein expression was detected by using enhanced chemiluminescence reagents (Beyotime, China) and analyzed by Quantity One 4.4.0 (Bio-Rad, USA).

\section{Immunofluorescence staining}

The immunofluorescence assays were performed to as previously described [20], Briefly, for tissues, samples were incubated for $2 \mathrm{~h}$ at room temperature in blocking buffer ( $5 \%$ bull serum albumin dissolved in PBS) and incubated overnight with the anti-LN5 (1:200; Santa Cruz, sc-20145) and anti-cytokeratin 7 (CK7, 1:200, Santa Cruz, sc-23876) antibodies in blocking buffer. For cell culture, Cells were fixed in ice-cold methanol and then blocked in $1 \%$ bovine serum albumin (BSA), and were further incubated in anti- LN- $\alpha 5$ antibody (1:1000; Santa Cruz, sc-20145) followed by a fluorescein isothiocyanate (FITC)-conjugated secondary antibody (Zhongsan Golden Bridge Crop) for $1 \mathrm{~h}$. Images were acquired with an Olympus BMX-60 microscope equipped with a cooled charge-coupled device sensi-camera (Cooke, Auburn Hills, MI, USA) and SlideBook software (Intelligent Imaging Innovations, Denver, CO, USA).

Table 2. Primers for quantitative RTPCR

\begin{tabular}{cc}
\hline & Sequence \\
\hline LN-A5 & Upstream: CCCACCGAGGACCTTTACTG \\
& Downstream: GGTGTGCCTTGTTGCTGTT \\
B-actin & Upstream: CATGTACGTTGCTATCCAGGC \\
& Downstream: CTCCTTAATGTCACGCACGAT
\end{tabular}




\section{Cellular Physiology Cell Physiol Biochem 2018;51:2030-2040

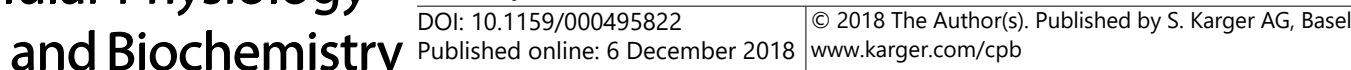

Zhang et al.: Role of Laminin (LN)- $\alpha 5$ in Preeclampsia Placentas

Cell proliferation assay

Cell proliferation was measured by using the Cell Counting Kit (CCK-8) (Beyotime, Jiangsu, China) according to the manufacturer's instruction. In short, transfected cells were seeded in 96-well plates in 100 $\mu \mathrm{L}$ of complete culture medium at a density of $1 \times 10^{4}$ cells per well and incubated for $24 \mathrm{~h}$. CCK-8 solution $(10 \mu \mathrm{L}$ per well) was added and then incubated for $2 \mathrm{~h}$. Absorbance was measured at a wavelength of 450 $\mathrm{nm}$ by the use of a spectrophotometer (Thermo, USA).

\section{Cell invasion assays}

Transwell assay was performed to evaluate the invasive capabilities of trophoblast in vitro. In the invasion assays, the upper side of the membrane was pre-coated with matrigel (BD Biosciences, San Jose, CA, USA) as described previously [21]. The lower chamber was added with cell culture medium containing $10 \% \mathrm{FBS}$, after incubated for $8 \mathrm{~h}$ at $37^{\circ} \mathrm{C}$, the cells on the upper well were removed by cotton swab, and the invades cells attached to the bottom side of the filter were fixed in methanol and stained. The invaded and migratory cells were observed and recorded under a microscopy (Olympus IX51, Japan) at a magnification of $200 \mathrm{X}$ in 10 random fields.

Flow cytometry

Flow cytometric analysis was used to detect apoptosis of trophoblast by the use of a fluorescein isothiocyanate (FITC) Apoptosis Detection kit (Key-GEN Biotech, Jiangsu, China) as previously described [22]. In brief, $1 \times 10^{6}$ cells were seeded in six-well plates with different groups for $48 \mathrm{~h}$, then the cells were harvested and washed with phosphate-buffered saline (PBS) for twice. Later, the cells were resuspended with $500 \mu \mathrm{L}$ of 7-AAD staining solution for $10 \mathrm{~min}$. within an hour, apoptosis rates were analyzed by FACS Vantage SE flow cytometer (BD Biosciences, San Jose, CA, USA).

\section{DNA methylation analysis}

Genomic DNA samples was extracted from normal and PE placentas, and purified by using DNAzol (Invitrogen). Purified DNA samples were further treated with sodium bisulfite (Sigma, Phoenix, USA), and then analyzed by bisulfite-sequencing PCR (BSP) as previously described [23]. The base sequence of LN- $\alpha 5$ is:

\section{TGGGCTGGGAGGAGCTGGTGGGCGCTCTGGGGGCCAGGGCGTCGTGGGGAGCGCTAGGGTCCCACCCGGGA CCCGGAGCTACGACCTGGGCTGGGGGCCCGGCGGCGCCGTCGTCCCACGGCCTGGCCCGAGGCCAGCAGGTG CCCCTTCCGGGAGGCGGCCGGGCCGGGGTCCGAAGGGTTAAGGCCGCCCGGCCGCCCCTCCСССTCCTCTCT ССTTCССССССССАССССGCСTCCCCGGACСTCTCCCCGGGGCTCGGGGCTCGGGCGCTCGGGCGGGCCGGG GCGGGGCCTGACGTCCGCGGGCGGAGCGAGCCCTGCCGGCCGCCTGGCTTCAGACCCGCCGGGCT.}

The methylation-specific primers were InF: 5'- TGGGTTGGGAGGAGTTGGT and InR: 5'AACCCRACRAATCTAAAACCAA. All analyses were conducted on the CpG site and region levels. Regional analysis was performed on predefined genomic regions ( $5 \mathrm{~kb}$ tiles, genes, promoters and CpG islands).

\section{Statistics and data analysis}

Data were presented as the mean \pm standard deviation (SD), and differences between groups were evaluated using Student's t test. Results were analyzed using SPSS 20.0 software (SPSS Statistics, Inc., Chicago, IL, USA). A value of $P<0.05$ was defined as statistically significant.

\section{Results}

\section{Clinical characteristics}

Differences in study participant demographics and clinical features between the 20 healthy pregnant women and 20 women with PE were evaluated. Women in early pregnancy were similar in age, gestational age and body mass index $(P>0.05)$. Women with PE had significantly higher proteinuria, systolic blood pressure and diastolic blood pressure as well as significantly lower neonatal birth weight compared with healthy women $(P<0.01)$ (Table 1). 
Fig. 1. $\mathrm{LN}-\alpha 5$ expression in human placenta from PE compared with normal pregnancy. A: The mRNA expression of $\mathrm{LN}-\alpha 5$ in $\mathrm{PE}$ and normal controls measured by qPCR. $\beta$-actin was used as control. B: Representative western blot bands of $\mathrm{LN}-\alpha 5$ in normal and PE placental tissues, and statistics of densitometry. C: Double I m m un ofluorescence Labeling (magnification $\times 400)$ of $\mathrm{LN}-\alpha 5$ in PE and normal placenta tissues. Red: CK7; green: LN- $\alpha 5$; blue: 4,6-diamidino-2phenylindole (DAPI). Data are presented as the mean \pm S.E.M, $\mathrm{n}=20$,

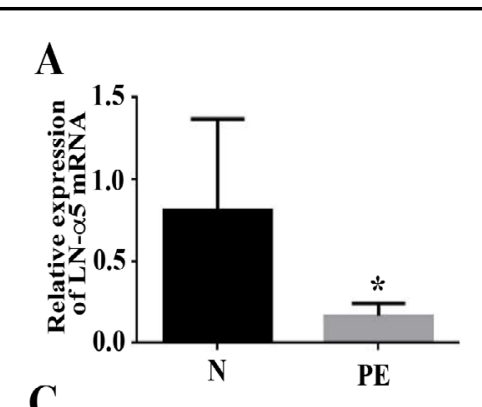

C
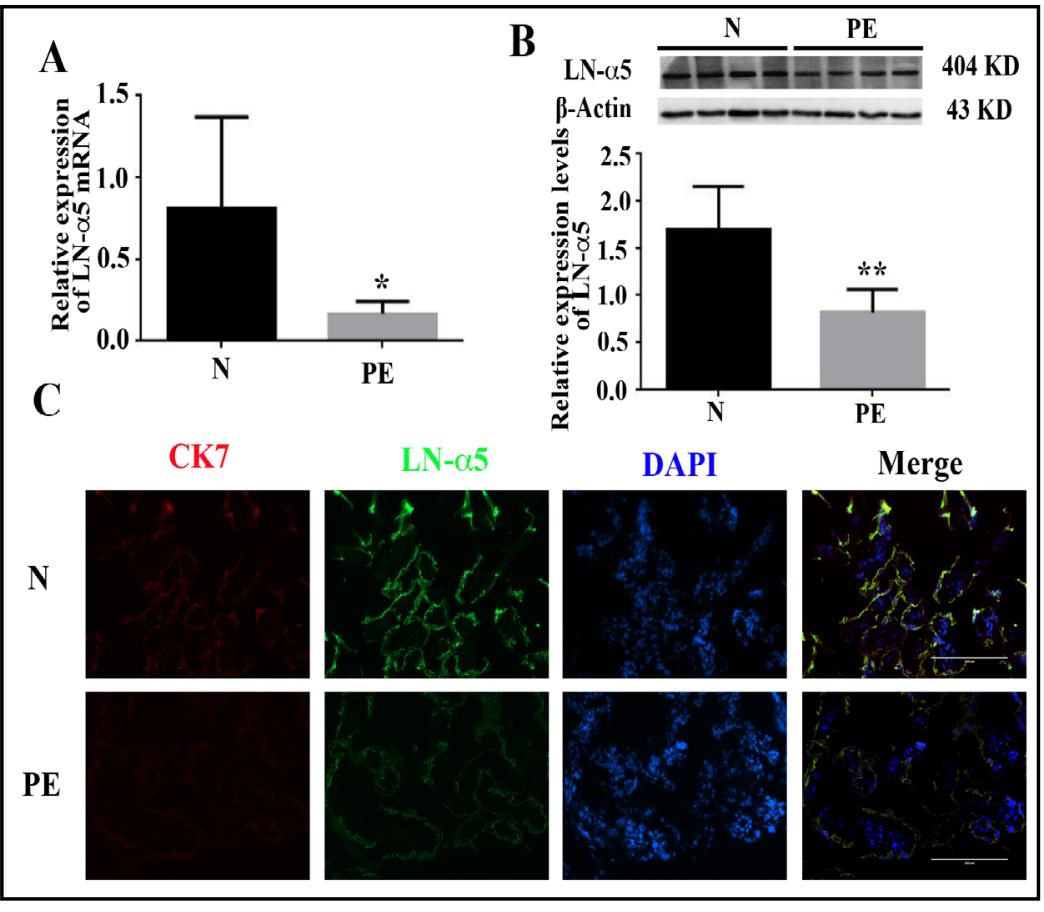
${ }^{*} \mathrm{P}<0.05,{ }^{* *} \mathrm{P}<0.01$.

PE placenta is associated with $L N-\alpha 5$ down-regulation To determine the transcription levels of $\mathrm{LN}-\alpha 5$ in placentas from PE patients and normal control. qPCR was performed and the results demonstrated a four-fold decrease of LN- $\alpha 5$ mRNA levels in PE placentas in compared with normal $(P<0.05$, Fig. $1 \mathrm{~A})$. This was further validated by western blotting and immunofluorescence staining, Consistently, western blots showed a two-fold decrease of $\mathrm{LN}-\alpha 5$ protein in the PE group compare to the normal group $(P$ $<0.01$, Fig. 1B). A reduction in LN$\alpha 5$ protein immunofluorescence staining was also detected (Fig. 1C). Taken together, these data clearly show that the expression of $\mathrm{LN}-\alpha 5$ is compromised in PE placentas.

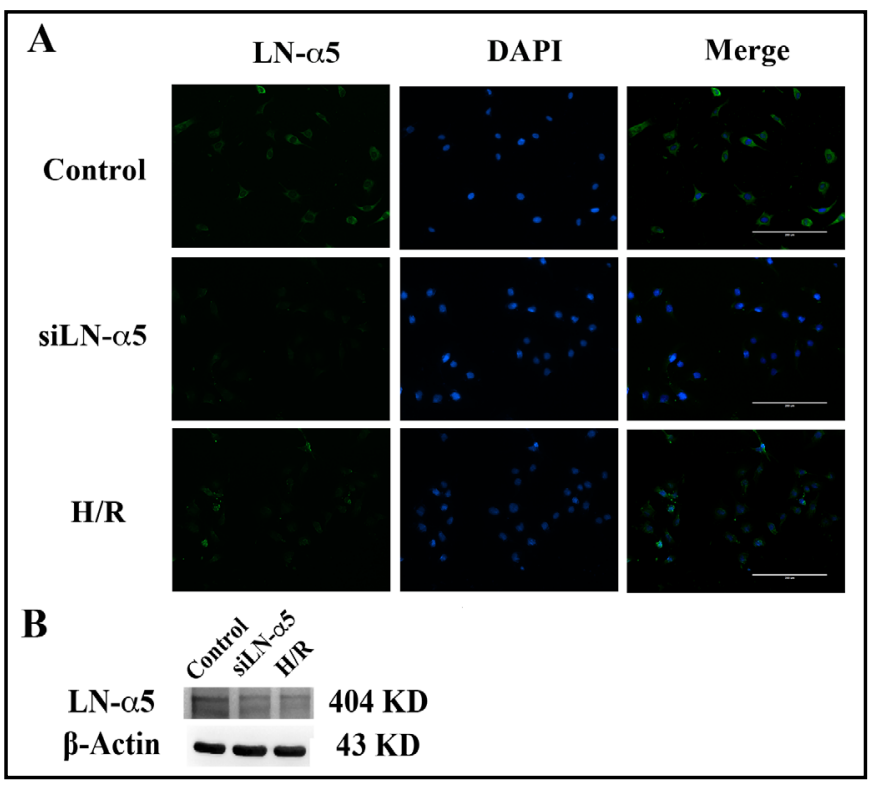

Fig. 2. Expression of $\mathrm{LN}-\alpha 5$ in HTR8/SVneo cells under different treatments. A:IF staining of $\mathrm{LN}-\alpha 5$ proteins in HTR8/SVneo cells, $\mathrm{LN}-\alpha 5$ is labelled in green, and nuclei is counterstained by DAPI (blue), 400X; B: representative western blot band of $\mathrm{LN}-\alpha 5$, $\beta$-actin was used as loading control, $n=3,{ }^{*} \mathrm{P}<0.05$. 


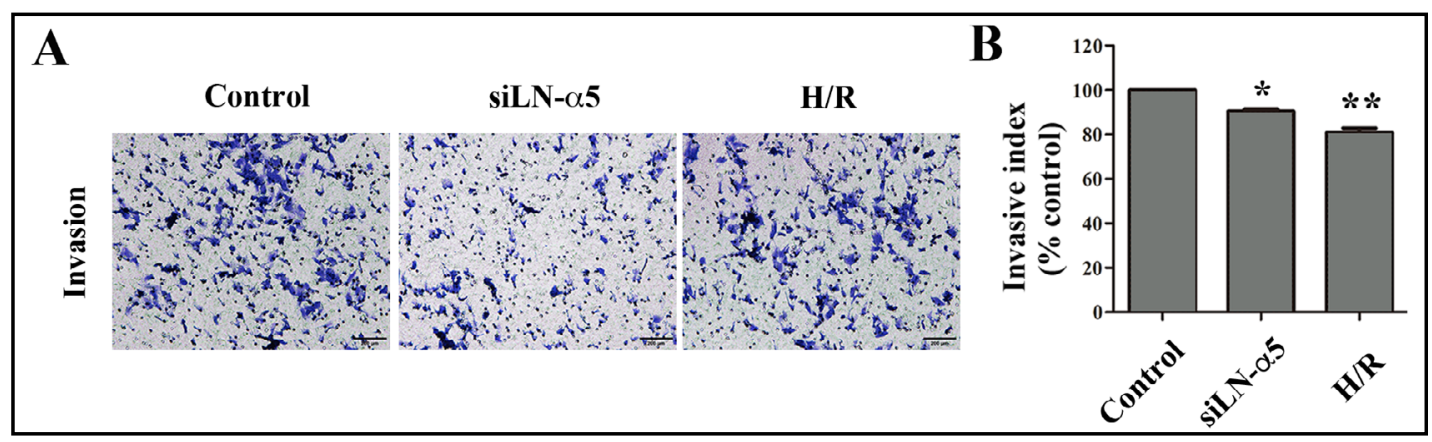

Fig. 3. Effects of different treatments on HTR8/SVneo cell invasion. A: Transwell invasion of cells in each groups; B: Statistical bar graphs of the invasion assays, 200X. Data were analyzed by analysis of variance (ANOVA) to assess significant differences. Original images were taken at 200 magnification, $\mathrm{n}=3,{ }^{*} \mathrm{P}<0.05,{ }^{* *}$ $\mathrm{P}<0.01$.

$L N-\alpha 5$ RNA silencing and $H / R$ treatment mimic PE-like $L N-\alpha 5$ expression reduction in HTR8/SVneo cells

For further investigate the effects and underlying mechanisms of compromised LN- $\alpha 5$ expression on PE development, LN- $\alpha 5$ deficiency and $\mathrm{PE}$ in vitro models are required. Thus HTR8/SVneo cells were given $\mathrm{LN}-\alpha 5$ RNAi or $\mathrm{H} / \mathrm{R}$ treatment. Then LN- $\alpha 5$ protein expression levels in different groups of HTR8/ SVneo cells were measured by western blots and immunofluorescence staining. As shown in Fig. 2, western

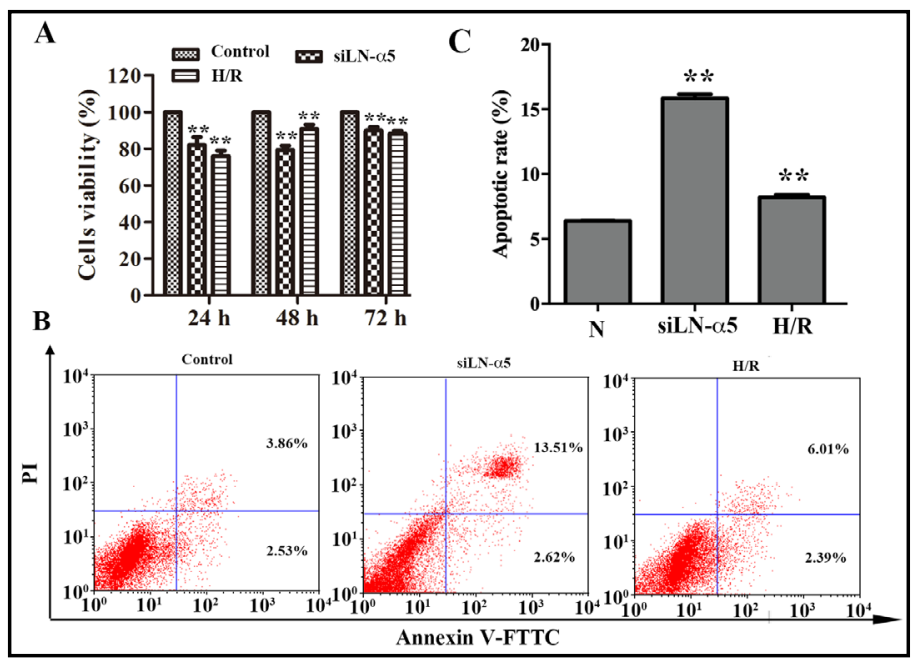

Fig. 4. Effects of different treatments on HTR8/SVneo cell proliferation and apoptosis. A: CCK-8 proliferation assay, $\mathrm{n}=3$, ** $\mathrm{P}<0.01$; B: Flow cytometric analysis of apoptosis; C: Statistical bar graphs of the apoptosis assays, $\mathrm{n}=3,{ }^{*} \mathrm{P}<0.05,{ }^{* *} \mathrm{P}<0.01$. blot results showed that the protein expression of LN- $\alpha 5$ in HTR8/SVneo cells was significantly reduced following LN- $\alpha 5$ siRNA silencing and H/R treatment compared with the control group $(P<0.05)$, which is further confirmed by immunofluorescence staining.

Assessment of the role of $L N-\alpha 5$ on cell invasion, proliferation, and apoptosis

To further investigate the role of $\mathrm{LN}-\alpha 5$ on invasion of HTR-8/SVneo cell, transwell matrigel invasion assay were used to evaluate the HTR8/SVneo cell invasion ability. Compared with control group, siRNA group significantly decreased the percentage of cells that showed invasion (Fig. 3A, 3B; ${ }^{* *} P<0.05$ ), and the H/R group had a more significantly decreased in invasion (Fig. $3 \mathrm{~A}, 3 \mathrm{~B}$; ${ }^{* *} P<0.01$ ).

Then the effects of $\mathrm{LN}-\alpha 5$ on trophoblast apoptosis and proliferation were assessed. Compared with the control group, siRNA and $\mathrm{H} / \mathrm{R}$ group significantly decreased proliferation of HTR8/SVneo cells by CCK-8 assay (Fig. 4A; ${ }^{* *} P<0.01$ ). We also analyzed the effect of LN$\alpha 5$ on the apoptosis using flow cytometry, as shown in Fig. 4B, 4C, the total early and late apoptosis were $16.1 \%$ and $8.4 \%$ in $\mathrm{LN}-\alpha 5$ silencing and the H/R and group, respectively, 


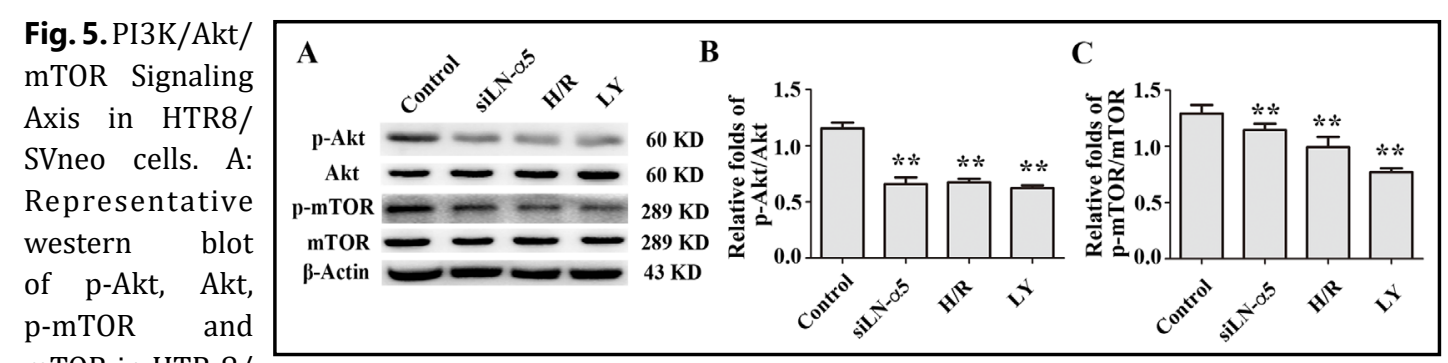
mTOR in HTR-8/

SVneo cells were treated with LN- $\alpha 5$ siRNA, H/R and LY, $\beta$-actin was used as loading control; B,C: Quantitative analyses of the difference in the phosphorylation of Akt and mTOR in HTR8/SVneo cells respectively, $n=3$, ${ }^{* *}$ $\mathrm{P}<0.01$.

which were significant increased compared with control group. $\left({ }^{* *} P<0.01\right)$. The data indicate that down-regulation of $\mathrm{LN}-\alpha 5$ reduces trophoblast cell proliferation and invasion, and increases cell apoptosis.

$L N-\alpha 5$ is essential for PI3K/AKT/mTOR signaling axis activation in HTR8/SVneo cells

To study the role of $\mathrm{LN}-\alpha 5$ in the regulation of PI3K/Akt/mTOR signaling pathway, HTR8/SVneo cells treated with PI3K pathway inhibitor LY or hypoxia/reoxgenation (H/R) were subjected to western blots. As shown in Fig. 5, western blots results showed that $\mathrm{LN}-\alpha 5$ silencing, $\mathrm{H} / \mathrm{R}$ and $\mathrm{LY}$ treatment all result in significant reduction in Akt and mTOR phosphorylation. These data suggest that down-regulation of $\mathrm{LN}-\alpha 5$ may cause PE by inhibiting PI3K signaling.

\section{$L N-\alpha 5$ promoter methylation wasn't differ between normal and PE placentas}

Abnormal methylation of LN- $\alpha 1, L N-\alpha 2, L N-\alpha 3, L N-\alpha 4, L N-\beta 1$ have been reported in breast carcinoma [24]. To future study the underlying mechanism of compromised LN- $\alpha 5$ expression in PE placenta, LN- $\alpha 5$ DNA methylation levels in normal and PE placentas were determined by performing BSP. The results demonstrated that $\mathrm{LN}-\alpha 5$ promoter region is hypermethylated in either normal or PE placenta, indicating that the DNA methylation might not the causative factor of reduction of $\mathrm{LN}-\alpha 5$ expression in PE placenta (Fig. 6).

\section{Discussion}

ECM is a non-cellular structure that is present in all tissues and can be divided into two separate types, the connective tissue matrix and BM [25]. The ECM provides structural support and promotes cellular functions including differentiation, adhesion, migration, proliferation, axonal growth and morphogenesis in many tissues [6, 26, 27]. LNs are a family of heterotrimeric glycoproteins and part of the ECM, and are important for multiple biological processes [5]. LN- $\alpha 5$ is widely expressed in BM containing multiple domains implicated in various biological processes, such as embryogenesis and placental development [11]. Evidence has demonstrated that knocking out LN- $\alpha 5$ genes in murine models cause embryonic lethal outcomes and considerable abnormalities in vascular and cytotrophoblast differentiation during placental development. These placental abnormalities are potentially caused by the lack of stable adhesion between cytotrophoblasts and $\mathrm{LN}-\alpha 5[10,28]$.

LNs are large non-collagenous glycoproteins that localized in the trophoblast and glomerular basement membrane. Some study found the serum LN levels were significantly higher in the PE than the normal pregnant group and it suggested LN plays an important role in implantation of the placenta [29]. Our group had previously demonstrated the LN- $\alpha 4$ had closely related in PE placenta, that $\mathrm{LN}-\alpha 4$ could promoted trophoblast cell in invasion, migration, and angiogenesis in PE placenta [30]. To future research the role of LN family in the PE placenta, $\mathrm{LN}-\alpha 5$ was investigated. 


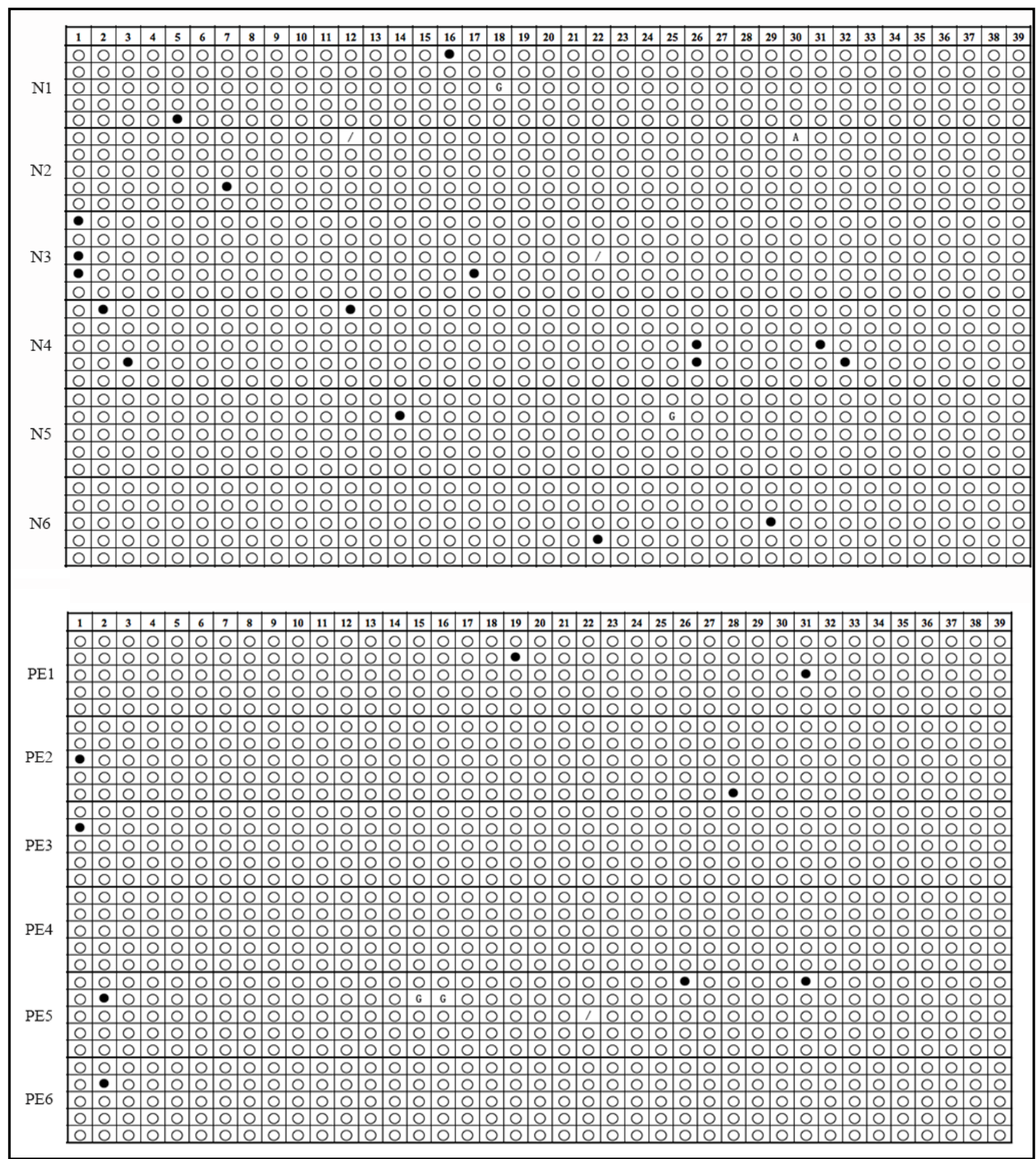

Fig. 6. DNA Methylation of Placental LN- $\alpha 5$. CpG sites of $L N-\alpha 5$ were included in the bisulfite genomic sequencing assay. A total of $39 \mathrm{CpG}$ sites in the normal and PE placentas were included, respectively. Each black circle represents a methylated $\mathrm{CpG}$ site, while the white circle represents an unmethylated $\mathrm{CpG}$. The LN- $\alpha 5$ promoter was not significantly altered in PE placentas compared with that in the normal ones, $n=6$, $\mathrm{P}>0.05$.

$\mathrm{LN}-\alpha 5$ has been shown to be critical for vasculature remodeling and angiogenesis, which illustrates the important role of this receptor in modulating cell function [31]. It is expressed in embryonic development $[10,32,33]$; therefore, we speculated that $\mathrm{LN}-\alpha 5$ might be involved in the regulation of trophoblast cell function during placentation. The aim of this study is to investigate the regulatory effects of $\mathrm{LN}-\alpha 5$ on the biological functions of trophoblast cells. In the present study, our results indicating that trophoblast cell proliferation, apoptosis, invasion are associated with $\mathrm{LN}-\alpha 5$ down-regulation in $\mathrm{PE}$, the result was similar with some researches that $\mathrm{LN}-\alpha 5$ was regulating an important aspect of trophoblast's morphogenesis and function, including migration, invasion, proliferation and apoptosis [10]. 
LN- $\alpha 5$ receptor signaling has been shown to regulate endothelial cell migration and proliferation via the PI3K pathway [13], which has been shown important in differentiation and invasion of trophoblast cells [34, 35]. Therefore, to explore the mechanism by which $\mathrm{LN}-\alpha 5$ regulates trophoblast cell function, we then assessed the effect of $\mathrm{LN}-\alpha 5$ expression on PI3K/Akt signaling in HTR8/SVneo cells. Along with our hypothesis, the result indicating that LN- $\alpha 5$ might regulate trophoblast cell function through the PI3K/AKT/mTOR signaling pathway, and the present study provides additional evidence supporting the activation of PI3K signaling in PE, this results were similar with some other studies that LN- $\alpha 5$ could enhance the invasiveness though the PI3k activation [13].

DNA methylation is a covalent modification applied to post-replicative DNA through the addition of a methyl group to the cytosine ring to form methyl cytosine, usually in the context of CpG dinucleotides. Discrete CpG rich regions, approximately $1 \mathrm{~kb}$ in size, are known as CpG islands and occur in over half of vertebrate genes [36]. DNA methylation is essential for normal development of extraembryonic tissues, particularly the invasive behavior of trophoblast cells [37]. The placenta is unique in that it is hypomethylated compared to somatic tissues [38], and some genes such as DNA methyltransferase 3A, DNA methyltransferase 1, and the human anti-angiogenic molecule sFlt-1 are hypomethylated in the placenta [39-41]. This suggests that there are global changes in DNA methylation in the placenta throughout pregnancy, contributing to differential gene expression across gestation. In the present study, we used BSP to investigate the CpG status of the $\mathrm{LN}-\alpha 5$ promoter, but failed to detect any significant difference in methylation between normal and PE placentas. In another study, our group also reported that compromised $\mathrm{LN}-\alpha 4$ in PE placenta is not associated with promoter methylation [30]. Taken together, these data strongly suggest that the LN family gene expression in PE placenta may not regulated by DNA methylation. Nevertheless, further studies with larger numbers of samples may be required to fully elucidate the mechanisms underlying expression regulation of $\mathrm{LN}-\alpha 5$ in PE.

\section{Conclusion}

In summary, our data demonstrated that PE placenta is associated with down-regulation of $\mathrm{LN}-\alpha 5$, and suppression of $\mathrm{LN}-\alpha 5$ expression compromises proliferation and invasion but promotes cell apoptosis in HTR-8/SVneo cells, possibly through the inhibition of the $\mathrm{PI} 3 \mathrm{~K} / \mathrm{AKT} / \mathrm{mTOR}$ signaling pathway. Our findings reveal new insights into the regulatory mechanisms of trophoblast invasion and contribute to the current understanding of the pathogenesis of PE.

\section{Acknowledgements}

Funding: this study was funded by the National Natural Science Foundation of China (81501286, 81471472, 81300508, 81300509, 81671488, 81601304, 81601305 ,81771613, $81771614,81701479,81701480$ ), Key Program of International Cooperation of NSFC (81520108013), Ph.D. Programs Foundation of Education of China (2013550311003), Innovation team Foundation of Chongqing Education Commission (CXTDX201601014), State Administration of foreign experts affairs P.R. China (Supported by 111 Project). Ethical approval: All procedures performed in studies involving human participants were in accordance with the ethical standards of the institutional and national research committee and with the 1964 Helsinki declaration and its later amendments. Informed consent: Informed consent was obtained from all individual participants included in the study. 


\section{Cellular Physiology Cell Physiol Biochem 2018;51:2030-2040

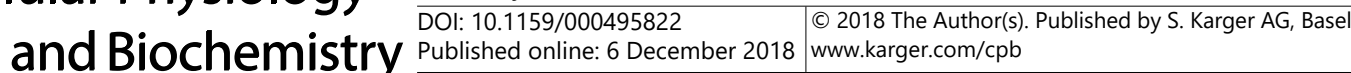

Zhang et al.: Role of Laminin (LN)- $\alpha 5$ in Preeclampsia Placentas

\section{Disclosure Statement}

All authors declare no conflict of interests.

\section{References}

1 Paridaens H, Gruson D: Pre-eclampsia: overview on the role of biomarkers in 2016. Ann Biol Clin (Paris) 2017;75:245-258.

-2 Say L, Chou D, Gemmill A, Tunçalp Ö, Moller AB, Daniels J, Gülmezoglu AM, Temmerman M, Alkema L: Global causes of maternal death: a WHO systematic analysis. Lancet Glob Health 2014;2:e323-333.

-3 Jia RZ, Ding GC, Gu CM, Huang T, Rui C, Wang YX, Lu Q: CDX2 enhances HTR-8/SVneo trophoblast cell invasion by altering the expression of matrix metalloproteinases. Cell Physiol Biochem 2014;34:628-636.

4 Shen Z, Wu Y, Chen X, Chang X, Zhou Q Zhou J, Ying H, Zheng J, Duan T, Wang K: Decreased maternal serum 2-methoxyestradiol levels are associated with the development of preeclampsia. Cell Physiol Biochem 2014;34:2189-2199.

5 Domogatskaya A, Rodin S, Tryggvason K: Functional diversity of laminins. Annu Rev Cell Dev Biol 2012;28:523-553.

6 Hynes RO: The evolution of metazoan extracellular matrix. J Cell Biol 2012;196:671-679.

7 Pulido D, Briggs DC, Hua J, Hohenester E: Crystallographic analysis of the laminin $\beta 2$ short arm reveals how the LF domain is inserted into a regular array of LE domains. Matrix Biol 2017;57-58:204-212.

8 Durbeej M: Laminins. Cell Tissue Res 2010;339:259-268.

-9 Savino W, Mendes-da-Cruz DA, Golbert DC, Riederer I, Cotta-de-Almeida V: Laminin-Mediated Interactions in Thymocyte Migration and Development. Front Immunol 2015;6:579.

10 Miner JH, Cunningham J, Sanes JR: Roles for laminin in embryogenesis: exencephaly, syndactyly, and placentopathy in mice lacking the laminin alpha5 chain. J Cell Biol 1998;143:1713-1723.

11 Miner JH: Laminins and their roles in mammals. Microsc Res Tech 2008;71:349-356.

12 Spenlé C, Simon-Assmann P, Orend G, Miner JH: Laminin $\alpha 5$ guides tissue patterning and organogenesis. Cell Adh Migr 2013;7:90-100.

13 Ritié L, Spenlé C, Lacroute J, Bolcato-Bellemin AL, Lefebvre O, Bole-Feysot C, Jost B, Klein A, Arnold C, Kedinger M, Bagnard D, Orend G, Simon-Assmann P: Abnormal Wnt and PI3Kinase signaling in the malformed intestine of LN-a5 deficient mice. PLoS One 2012;7:e37710.

14 Gao J, DeRouen MC, Chen CH, Nguyen M, Nguyen NT, Ido H, Harada K, Sekiguchi K, Morgan BA, Miner JH, Oro AE, Marinkovich MP: Laminin-511 is an epithelial message promoting dermal papilla development and function during early hair morphogenesis. Genes Dev 2008;22:2111-2124.

-15 Simone Sampalolo, Filomena Napolitano, Alfonsina Tirozzi, Mafalda Giovanna Reccia, Luca Lombardi, Olipia Farina, Adriano Barra, Ferdinando Cirillo, Mariarosa Anna Beatrice Melone, Fernando Gianfrancesco, Giuseppe Di lorio, Teresa Esposito: Identification of the first dominant mutation of LAMA5 gene causing a complex multisystem syndrome due to dysfunction of the extracellular matrix. J Med Genet 2017;54:710720 .

16 Engelman JA., Luo J, Cantley LC: The evolution of phosphatidylinositol 3-kinases as regulators of growth and metabolism. Nature reviews Genetics 2006;7:606-619.

17 Hung TH, Chen SF, Li MJ, Yeh YL, Hsieh TT: Differential effects of concomitant use of vitamins C and E on trophoblast apoptosis and autophagy between normoxia and hypoxia-reoxygenation. PLoS One 2010;5:e12202.

18 Takáč T, Pechan T, Samajová 0, Samaj J: Vesicular trafficking and stress response coupled to PI3K inhibition by LY294002 as revealed by proteomic and cell biological analysis. J Proteome Res 2013;12:4435-4448.

19 Gao L, Qi HB, Kamana KC, Zhang XM, Zhang H, Baker PN: Excessive autophagy induces the failure of trophoblast invasion and vasculature: possible relevance to the pathogenesis of preeclampsia. J Hypertens 2015;33:106-117.

20 Liao Z, Nan G, Yan Z, Zeng L, Deng Y, Ye J, Zhang Z, Qiao M, Li R, Denduluri S, Wang J, Wei Q, Geng N, Zhao L, Lu S, Wang X, Zhou G, Luu HH, Haydon RC, He TC1, Wang Z: The Anthelmintic Drug Niclosamide Inhibits the Proliferative Activity of Human Osteosarcoma Cells by Targeting Multiple Signal Pathways. Curr Cancer Drug Targets 2015;15:726-738. 


\section{Cellular Physiology Cell Physiol Biochem 2018;51:2030-2040 and Biochemistry DOl: 10.1159/000495822 20 O 2018 The Author(s). Published by S. Karger AG, Basel

21 Yang Z, Bai B, Luo X, Xiao X, Liu X, Ding Y, Zhang H, Gao L, Li J, Qi H: Downregulated Krüppel-like factor 8 is involved in decreased trophoblast invasion under hypoxia-reoxygenation conditions. Reprod Sci 2014;21:72-81.

22 Algharabil J, Kintner DB, Wang Q, Begum G, Clark PA, Yang SS, Lin SH, Kahle KT, Kuo JS, Sun D: Inhibition of $\mathrm{Na}(+)-\mathrm{K}(+)-2 \mathrm{Cl}(-)$ cotransporter isoform 1 accelerates temozolomide-mediated apoptosis in glioblastoma cancer cells. Cell Physiol Biochem 2012;30:33-48.

-23 Guo X, Jing C, Li L, Zhang L, Shi Y, Wang J, Liu J, Li C: Down-regulation of VEZT gene expression in human gastric cancer involves promoter methylation and miR-43c. Biochem Biophys Res Commun 2011;404:622627.

-24 Simonova OA, Kuznetsova EB, Poddubskaya EV, Kekeeva TV, Kerimov RA, Trotsenko ID, Tanas AS, Rudenko VV, Alekseeva EA, Zaletayev DV, Strelnikov VV: DNA methylation in the promoter regions of the laminin family genes in normal and breast carcinoma tissues. Mol Biol (Mosk) 2015;49:598-607.

25 Bonnans C, Chou J, Werb Z: Remodelling the extracellular matrix in development and disease. Nat Rev Mol Cell Biol 2014;15:786-801.

26 Frantz C, Stewart KM, Weaver VM: The extracellular matrix at a glance. J Cell Sci 2010;123:4195-4200.

27 Pozzi A, Yurchenco PD, Lozzo RV: The nature and biology of basement membranes. Matrix Biol 2017;5758:1-11.

28 Wiradjaja, F, DiTommaso T, Smyth I: Basement Membranes in Development and Disease. Birth Defects Res C Embryo Today 2010;90:8-31.

29 Furuhashi N, Kimura H, Nagae H, Yajima A, Kimura C, Saito T: Serum laminin levels in normal pregnancy and preeclampsia. Gynecol Obstet Invest 1993;36:172-175.

30 Shan N, Zhang X, Xiao X, Zhang H, Tong C, Luo X, Chen Y, Liu X, Yin N, Deng Q, Qi H: Laminin a4 (LAMA4) expression promotes trophoblast cell invasion, migration, and angiogenesis, and is lowered in preeclamptic placentas. Placenta 2015;36:809-820.

-31 Kikkawa Y, Miner JH: Molecular dissection of laminin alpha 5 in vivo reveals separable domain-specific roles in embryonic development and kidney function. Dev Biol 2006;296:265-277.

-32 Gopal SK, Greening DW, Zhu HJ, Simpson RJ, Mathias RA: Transformed MDCK cells secrete elevated MMP1 that generates LN-A5 fragments promoting endothelial cell angiogenesis. Sci Rep 2016;6:28321.

-33 Lin C, Werner R, Ma L, Miner JH: Requirement for basement membrane laminin $\alpha 5$ during urethral and external genital development. Mech Dev 2016;141:62-69.

34 Soares MJ, Chakraborty D, Renaud SJ, Kubota K, Bu P, Konno T, Rumi MA: Regulatory pathways controlling the endovascular invasive trophoblast cell lineage. J Reprod Dev 2012;58:283-287.

-35 Fisher SJ: Why is placentation abnormal in preeclampsia. Am J Obstet Gynecol 2015;213:S115-122.

-36 Li E, Zhang Y: DNA Methylation in Mammals. Cold Spring Harb Perspect Biol 2014;6:a019133.

-37 Branco MR, King M, Perez-Garcia V, Bogutz AB, Caley M, Fineberg E, Lefebvre L, Cook SJ, Dean W, Hemberger M, Reik W: Maternal DNA Methylation Regulates Early Trophoblast Development. Dev Cell 2015;36:152-163.

-38 Cotton AM, Avila L, Penaherrera MS, Affleck JG, Robinson WP, Brown CJ : Inactive X chromosome-specific reduction in placental DNA methylation. Hum Mol Genet 2009;18:3544-3552.

-39 Jia Y, Li T, Huang X, Xu X, Zhou X, Jia L, Zhu J, Xie D, Wang K, Zhou Q, Jin L, Zhang J, Duan T: Dysregulated DNA Methyltransferase 3A Upregulates IGFBP5 to Suppress Trophoblast Cell Migration and Invasion in Preeclampsia. Hypertension 2017;69:356-366.

40 Mukhopadhyay A, Ravikumar G, Meraaj H, Dwarkanath P, Thomas A, Crasta J, Thomas T, Kurpad AV, Sridhar TS: Placental expression of DNA methyltransferase 1 (DNMT1): Gender-specific relation with human placental growth. Placenta 2016;48:119-125.

41 Kühnel E, Kleff V, Stojanovska V, Kaiser S, Waldschütz R, Herse F, Plösch T, Winterhager E, Gellhaus A: Placental-Specific Overexpression of sFlt-1 Alters Trophoblast Differentiation and Nutrient Transporter Expression in an IUGR Mouse Model. J Cell Biochem 2017;118:1316-1329. 